\title{
Evidence of son preference and resulting demographic and health outcomes in Pakistan
}

\author{
Zeba Sathar \\ Population Council \\ Gul Rashida \\ Sabahat Hussain \\ Anushe Hassan
}

Follow this and additional works at: https://knowledgecommons.popcouncil.org/departments_sbsr-pgy

Part of the Demography, Population, and Ecology Commons, Family, Life Course, and Society Commons, Gender and Sexuality Commons, and the International Public Health Commons How does access to this work benefit you? Let us know!

\section{Recommended Citation}

Sathar, Zeba, Gul Rashida, Sabahat Hussain, and Anushe Hassan. 2015. "Evidence of son preference and resulting demographic and health outcomes in Pakistan." Islambad: Population Council. 


\section{Evidence of Son Preference and Resulting Demographic and Health Outcomes in Pakistan}

\section{Authors:} Zeba A. Sathar Gul Rashida Sabahat Hussain Anushe Hassan 



\section{POPULATION \\ COUNCIL \\ Ideas. Evidence. Impact.}

The Population Council confronts critical health and development issues-from stopping the spread of HIV to improving reproductive health and ensuring that young people lead full and productive lives. Through biomedical, social science, and public health research in 50 countries, we work with our partners to deliver solutions that lead to more effective policies, programs, and technologies that improve lives around the world. Established in 1952 and headquartered in New York, the Council is a nongovernmental, non-profit organization governed by an international board of trustees.

Population Council

House 7, Street 62, F-6/3, Islamabad, Pakistan

Tel: 92518445566

Fax: 92512821401

Email: info.pakistan@popcouncil.org

Web: www.popcouncil.org 



\section{Table of Contents}

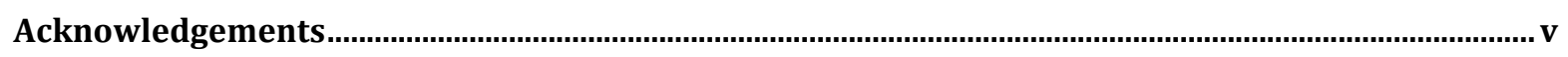

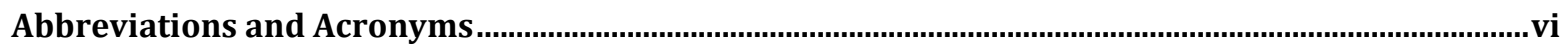

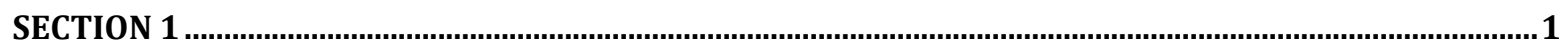

INTRODUCTION

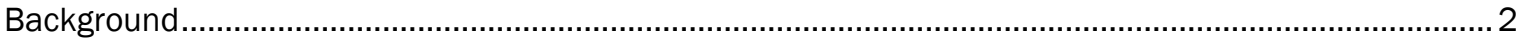

Rationale

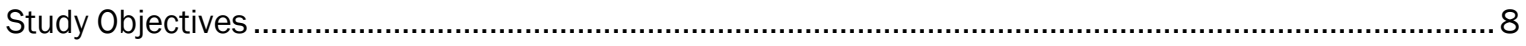

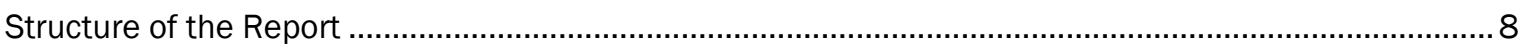

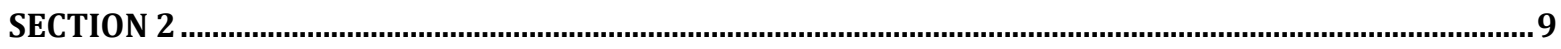

METHODOLOGY

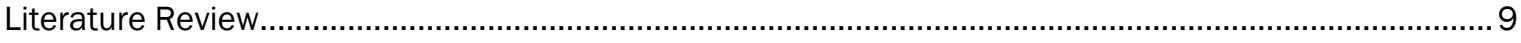

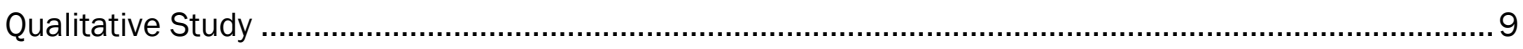

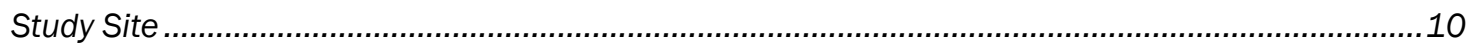

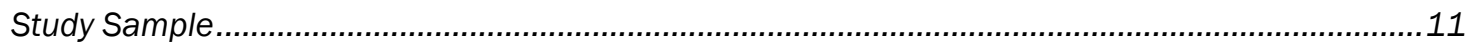

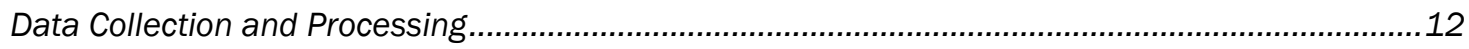

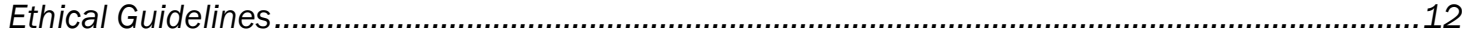

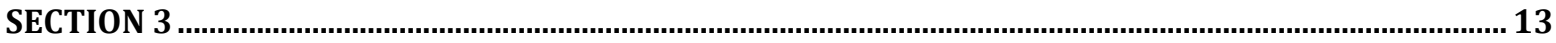

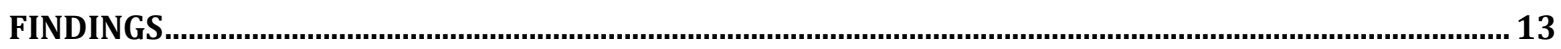

Prevalence of Son Preference ...................................................................................................

Effect of Son Preference on Fertility Preferences and Behavior ....................................................15

Effect of Education, Wealth and Region on Son Preference .........................................................17

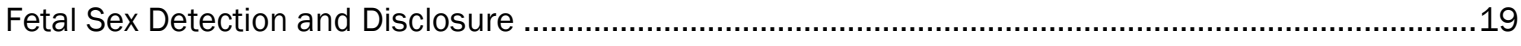

Availability and Usage of Fetal Sex Detection Technology.............................................................19

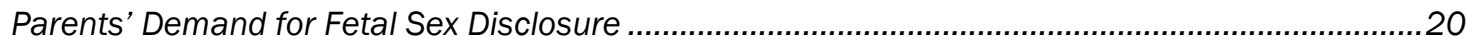

The Supply Side - Providers' Response to Client Requests for Disclosure .......................................21

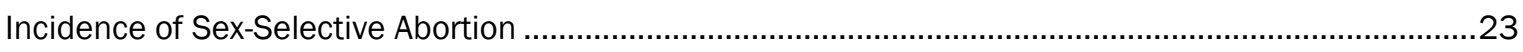

The Abortion Law, Its Enforcement and Provider Awareness.............................................................23

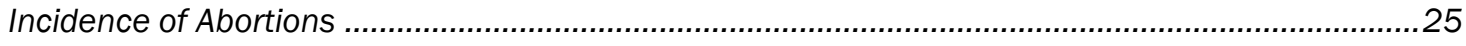

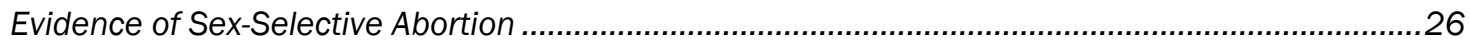


Social, Health and Legislative Interventions to Prevent Sex Selection ..................................................29

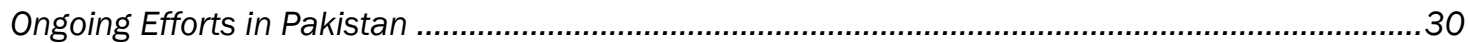

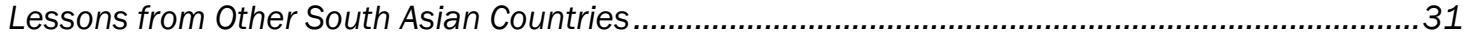

Providers' Recommendations for Countering the Risk of Sex-Selective Abortions............................32

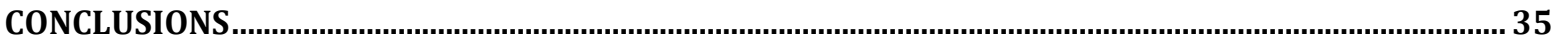

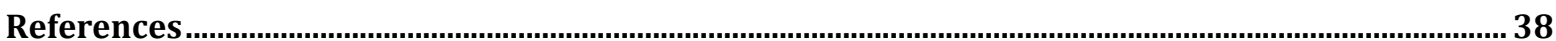




\section{Acknowledgements}

The study team is indebted to UKAid for funding this study, which is the first of its kind in Pakistan.

The team wishes to express our deep gratitude to Dr. Shireen Jejeebhoy (Population Council, India) for her technical inputs, guidance and support throughout the study and in preparation of the report.

We would like to acknowledge the comments of the external reviewer, Dr. Farrukh Zaman.

We would like to express our sincere thanks to Dr. Ali Mir for his valuable inputs and guidance throughout the study. We highly acknowledge the contribution of Maqsood Sadiq for the help in data analysis and calculating sex ratios. Our special thanks to Abdur Rauf Khan and Usman Asif for preparing the matrices and assisting in analyzing the data.

We also very much appreciate and acknowledge the contribution of our study team member Dr. Afshan Zaman for her untiring efforts in helping to identify and locate the respondents, assist in conducting interviews and transcribing them. We highly acknowledge the contribution of Ms. Kiren Khan who has provided excellent editorial support.

We owe special thanks to all the study participants who spared their time to answer our questions and provided the useful information. 


\section{Abbreviations and Acronyms}

$\begin{array}{ll}\text { CSR } & \text { Child Sex Ratios } \\ \text { FSSP } & \text { Female School Stipend Program } \\ \text { GoP } & \text { Government of Pakistan } \\ \text { IRB } & \text { Institutional Review Board } \\ \text { KP } & \text { Khyber Pakhtunkhwa } \\ \text { NIPS } & \text { National Institute of Population Studies } \\ \text { PDHS } & \text { Pakistan Demographic and Health Survey } \\ \text { PHC } & \text { Primary Health Care } \\ \text { PSLM } & \text { Pakistan Social and Living Standards Measurement Survey } \\ \text { SBCC } & \text { Social and Behavior Change Communication } \\ \text { SDPI } & \text { Sustainable Development Policy Institute } \\ \text { SRB } & \text { Sex Ratios at Birth }\end{array}$




\section{SECTION 1}

\section{INTRODUCTION}

Like much of the rest of South Asia, Pakistan has a highly patriarchal society. Consequently, the desire for sons is a dominant and widely prevalent cultural value that is reinforced by feudal kinship systems, which permeate many parts of the country (UNFPA 2012). While the reliance on sons is stronger in rural areas because of agricultural work and the tying of land ownership with male inheritance, even in other areas, boys are seen to be important in carrying on the family name and taking care of parents in old age.

On the other hand, daughters are seen as an expense and an economic burden in both rural and urban areas, especially in view of the increasing price of dowry (Royan and Zaidi 2011; Zubair et al. 2006; Fikree and Pasha 2004). A mere 22 percent of women participate in the labor force (Pakistan Labour Force Survey 2012-13), and this role of women as productive and economically empowered agents is largely confined to urban areas. The majority of women remain economically dependent on male household members and are unlikely to be contributing to household income.

In an international comparison, Bongaarts (2013) ranked Pakistan as having the second highest Desired Sex Ratio for Boys out of a total of 61 countries, and this son preference is validated by results of successive Pakistan Demographic and Health Surveys (PDHSs). Studies have noted the profound implications of this preference on fertility decisions: Muhammad (2009) finds that the desire for a son when a couple has only or mostly daughters is stronger than the desire to have a daughter when a couple has only or mostly sons. More insidiously, son preference has a proven impact on child care and on the child sex ratio in Pakistan (Guilmoto 2009), with boys receiving a disproportionate share of their parents' resources, and the nutritional, health, educational and psychological needs of girls commonly being neglected. For this reason, in 2000-05, Pakistan was one of the few countries in the world to have higher female than male mortality below the age of five (Guilmoto 2009).

Such marked preference for sons can translate into sex-selective abortions and uneven sex ratios at birth (SRBs) when fetal sex determination technology is available and permitted. This is especially true where fertility rates are declining: as families begin to have fewer children, their desire to determine the gender of the child increases (Guilmoto 2009). Indeed, the discriminatory practice of prenatal sex selection has already taken root elsewhere in the region, leading to unequal SRBs and child sex ratios (CSRs) in several South Asian societies. 
This report forms part of a research project supported by UKAid and conducted by the Population Council's Bangladesh, India and Pakistan offices, and the Centre for Research, Environment, Health and Population Activities (CREHPA), Nepal, to explore the issue of gender-biased sex selection in these countries and make evidence-based recommendations for responding to adverse sex ratios at birth. It presents the research conducted in Pakistan, which comprised a review of literature and an exploratory qualitative study of reproductive healthcare providers' perspectives on the risk and incidence of prenatal sex selection in Karachi. Companion reports explore key issues of relevance in India, Bangladesh, and Nepal.

\section{Background}

Sex selection in favor of boys is a symptom of pervasive social, cultural, political and economic injustices against women, and a manifest violation of women's human rights (Gilles and Feldman-Jacobs 2012;

Guilmoto 2011). The clearest indicator of its prevalence in a society is a distorted sex ratio at birth. This is the ratio of male to female births in a population, multiplied by 100 . The normal value for SRB ranges from 102 to 107 male babies for every 100 female babies born.

In Pakistan, precise SRB figures for Pakistan are not available because the national censuses have not thus far reported this ratio. In the absence of a fully developed vital registration system, birth data is lacking and therefore vital events are mostly estimated on the basis of household surveys. ${ }^{1}$ SRB has been reported by the Pakistan Demographic and Health Surveys, the latest of which was conducted in 2012-13 based on a representative sample of nearly 13,000 households. The PDHS 2012-13 reported Pakistan's overall SRB to be 102.5 , but its detailed findings showed that sex ratios at birth are slightly higher-albeit within the normal range-in the urban areas and at higher parities (Table 1).

1 In 2012-13, it was estimated that only 34 percent of male births and 33 percent of female births had been registered (NIPS 2013). 
Table 1: Sex Ratios at Birth, including Children Who Later Expired, by demographic characteristics 2006-7 \& 2012-13

\begin{tabular}{llcc}
\hline & & PDHS 2006-07 & PDHS 2012-13 \\
\hline Pakistan & & 113.1 & 102.5 \\
\hline \multirow{2}{*}{ Urban Rural Differentials } & Urban & 118.9 & 103.9 \\
& Rural & 110.7 & 101.9 \\
\hline \multirow{3}{*}{ Mother's Education } & No education & 110.4 & 105.8 \\
& Primary & 123.4 & 95.4 \\
& Secondary & 112.6 & 99.8 \\
& Higher & 118.4 & 104.5 \\
\hline \multirow{3}{*}{ Birth Order } & First Child & 133.1 & 104.7 \\
& Second & 100.6 & 92.7 \\
& Third & 121.5 & 108.8 \\
& Fourth & 107.1 & 104.5 \\
\hline \multirow{3}{*}{ Provincial Differences } & Punjab & 116.2 & 101.0 \\
& Sindh & 106.2 & 110.3 \\
& Khyber Pakhtunkhwa & 115.7 & 96.6 \\
& Baluchistan & 106.3 & 97.7 \\
\hline
\end{tabular}

Sources: PDHS 2006-07 and PDHS 2012-13.

When compared to the results of PDHS 2006, the results of PDHS 2013 indicate that sex ratios at birth have declined significantly. However, this balancing can be attributed to better reporting of female births and children, rather than an actual increase in female births or survival. This was the conclusion reached by an earlier study reporting on sex ratios at birth from various surveys conducted between 1990 and 2003 (Mahmood 2007). Mahmood (2003) found underreporting of 6-7 percent of female children in Pakistan in the 1998 Census. Training of DHS interviewers has therefore focused on ensuring the inclusion of girl children.

While direct evidence of prenatal sex selection in Pakistan is negligible, and sex ratios at birth seem to have improved, the country's child sex ratios are quite skewed, indicating higher female mortality among under-five year olds (Table 2). 
Table 2: Child Sex Ratios (1-5 years) by demographic characteristics, 2006-7 and 2012-13

\begin{tabular}{llcc}
\hline & & PDHS 2006-07 & PDHS 2012-13 \\
\hline Pakistan & & 110.8 & 106.4 \\
\hline \multirow{2}{*}{ Urban Rural Differentials } & Urban & 115.9 & 108.2 \\
& Rural & 108.7 & 105.7 \\
\hline \multirow{3}{*}{ Mother's Education } & No education & 110.6 & 105.2 \\
& Primary & 107.7 & 109.1 \\
& Secondary & 108.8 & 104.8 \\
& Higher & 126 & 113.8 \\
\hline \multirow{3}{*}{ Birth Order } & First Child & 114.2 & 113.6 \\
& Second & 104.2 & 108.7 \\
& Third & 120.1 & 96.1 \\
& Fourth & 109.1 & 105.6 \\
\hline \multirow{3}{*}{ Provincial Differences } & Punjab & 110.9 & 107.8 \\
& Sindh & 108.7 & 105.5 \\
& Khyber Pakhtunkhwa & 110.9 & 103.4 \\
& Baluchistan & 121.6 & 101.9 \\
\hline
\end{tabular}

Sources: PDHS 2006-07 and PDHS 2012-13.

Biologically, female babies have an advantage over male babies; they are naturally expected to be healthier and have a higher chance of survival through childhood if the same treatment and care is provided to them as male babies. Yet, as mentioned earlier, according to the United Nations Population Division, Pakistan was one of the few countries in the world to have higher female than male mortality below the age of five in 2000-05 (Guilmoto 2009). The under-five mortality sex ratio (ratio of male mortality rate to female mortality rate) is 105.4 and there are 25,000 excess female deaths among under-fives every year (Guilmoto 2011). Table 2 shows that while child sex ratios in Pakistan have improved since 2006, they remain disturbed in urban and developed regions as well as in families with higher educational attainment.

This unevenness in the child sex ratio is attributed to differential treatment of girls in regard to resource allocation. The most common causes of under-five deaths for boys are related to neonatal complications, while causes of deaths for girls were more likely to be related to infectious diseases (Zaidi, 2013). Fikree and Pasha (2004) show that a girl under five is 30-50 percent more likely to die than a boy the same age due to neglect that can take the form of inadequate nutrition, absence of preventive care (e.g., immunization) or non-provision of health care for illnesses. Several other studies have similar findings. ${ }^{2}$

\footnotetext{
2 For example, Hussain et al. (2000) found substantial evidence of discrimination against daughters with regard to food allocation and access to health services; Qadir et al. (2011) found that medical care was sought more for sons than for daughters in
} 
Furthermore, recent informal accounts indicate a far higher risk to girls of infanticide and abandonment by parents. Records at the Edhi Foundation, a nonprofit social welfare program in Pakistan, indicate that nine out of ten newborn babies killed and dumped in the country in 2010 were girls (Sayah 2011). The Foundation has also noted that the children abandoned at its doorsteps are mostly girls (Nosheen and Schellman 2012), and other incidents of girl abandonment and infanticide have also been documented across Pakistan (Mansoor 2011; Saleem 2011; Pakistan Times 2013; Karimjee 2014).

Son preference in Pakistan thus appears to manifest through unequal child sex ratios, resulting from gender bias after birth, as opposed to high sex ratios at birth.

At the level of the overall population, data from all five censuses conducted in Pakistan since 1951 indicates that the male population has consistently outnumbered the female population (Figure 1), although the sex ratio has declined progressively (Figure 2). As of the last census, which was held in 1998, Pakistan's overall sex ratio was 108.5 males per 100.0 females, i.e., 925 females per 1000 males, with conspicuous skewing in Baluchistan, Sindh and Islamabad (Table 3).

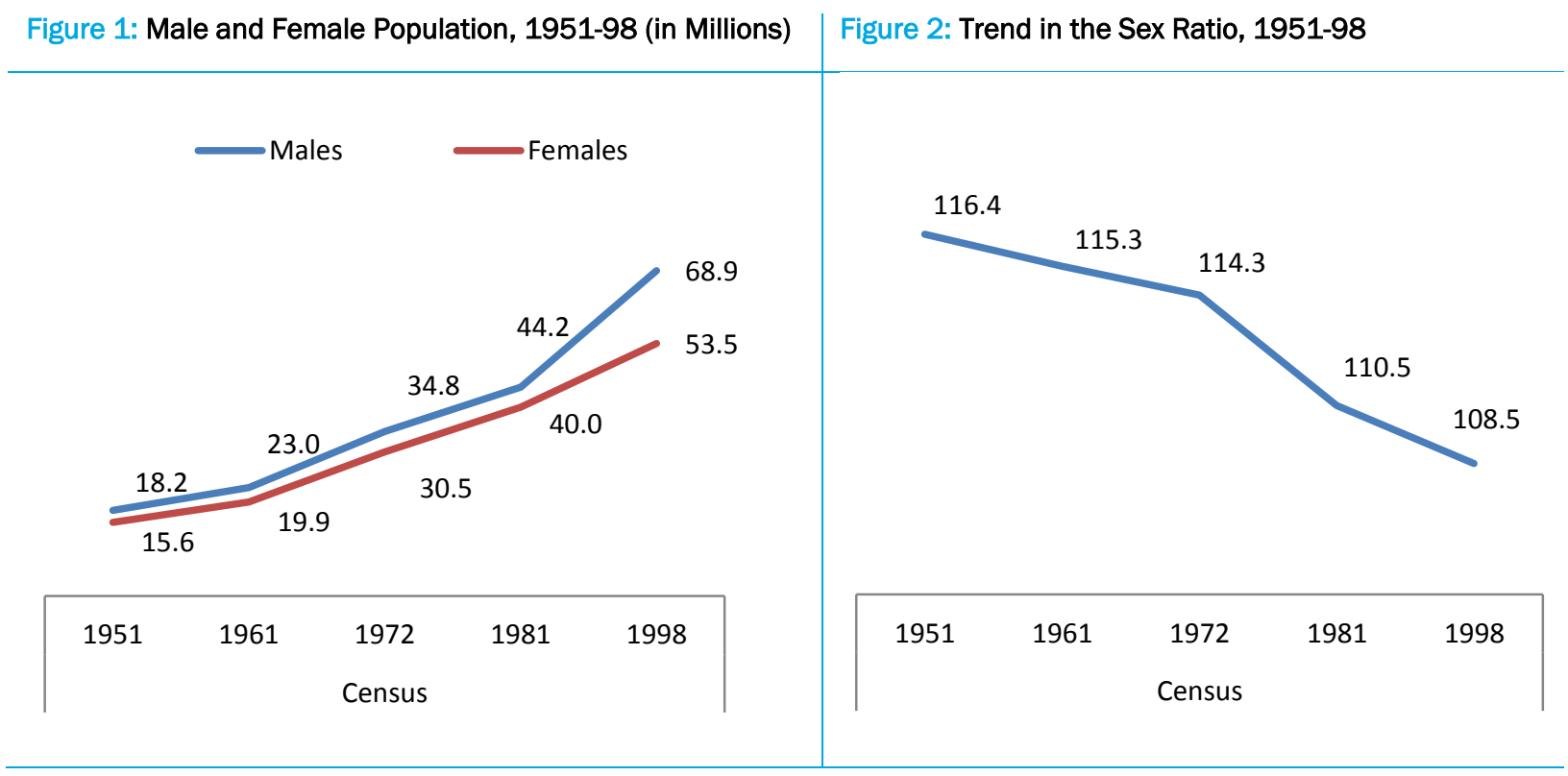

Source: Pakistan Bureau of Statistics

Islamabad; and Gangadharan and Maitra (2000) found higher mortality of girls in the age group 1-5 years in Pakistan reflecting discrimination against girls in the form of lower health care and provision of other resources. 
Table 3: Provincial Sex Ratios in Pakistan, 1998

\begin{tabular}{lc}
\hline Provincial & Census 1998 \\
\hline Pakistan & 108.5 \\
Khyber Pakhtunkhwa & 105.0 \\
Baluchistan & 114.6 \\
Sindh & 112.2 \\
Punjab & 107.2
\end{tabular}

Source: 1998 Census

According to Pakistan's most recent National Census, conducted 17 years ago (Federal Bureau of Statistics 1998), there were 5,983,526 missing women in 1998 (Hudson and Den Boer 2005). In 2003, the country's missing women were a staggering 7.8 percent of the total female population (Klasen and Wink 2003). Guilmoto (2011) calculated the number of missing women from Pakistan in 2010 to be $2,833,000$, a substantial 3.3 percent of the total female population in the country. The growing number of missing women speaks of a culture in which gender inequality is deeply rooted. Patriarchal structures reinforce son preference and a climate of violence and discrimination against women and girls in society.

\section{Rationale}

Guilmoto (2009) attributes distortions in the SRB to the convergence of three interlinked factors: (1) persistence of patriarchal norms and non-egalitarian gender roles and consequent son preference; (2) fertility decline and preference for smaller families; and (3) technological advances that permit the detection of the sex of the fetus. These three conditions are currently coming together in pockets of Pakistani society. Son preference persists and is poignantly reflected in Pakistan's distorted child sex ratios: notably, India's current challenge of pronounced SRB distortions was preceded by a similar skewing of the child sex ratio; the sex ratio at birth was upset only after early fetal sex detection technology became available in the 1980s (Population Council, forthcoming a).

With regard to the second precursor to skewed sex ratios at birth, i.e., declining fertility, Pakistan's situation is somewhat different. Estimates from the PDHS 2006-07 and 2012-13 suggest that the decline in fertility rates has slowed down compared to the 1990s, and the country's overall total fertility rate remains higher than the rest of the region at 3.8. But although the higher fertility implies less control over reproductive choices and, consequently, sex preferences not really coming into play, in reality, the high fertility is itself driven by a desire for sons-more births maximize the chance of having at least one son (Zaidi 2013). Moreover, fertility decline in Pakistan has been uneven, and urban women and those with more than secondary education are moving towards replacement fertility (PDHS 2013). Among the urban and educated families where rapid fertility decline has been witnessed, continued strong preference for sons is likely to become a contentious factor as parents make more confined choices about numbers of children (Sathar 2007). Studies show that women with lower fertility, better education or socioeconomic status, and more exposure to media are more likely to pursue the deliberate desire to control the sex of their next child (Fikree and Pasha 2004; Royan and Zaidi 2011), as they have the means to access 
prenatal care facilities (Fatmi and Avan 2002). Thus, while son preference currently affects fertility in the form of a desire for more children, as Pakistan draws closer to its goals of higher contraceptive prevalence and lower total fertility rates, it is possible that couples desiring smaller families will seek ways to determine the gender of the limited number of children they plan to have (Guilmoto 2009).

Finally, with respect to the third factor underlying distorted SRBs, i.e., availability of fetal sex detection services, the latest PDHS indicates nearly universal availability and widespread use of ultrasound technology that can detect the sex of the fetus in the second trimester of pregnancy (NIPS 2013). However, more advanced diagnostic technologies that enable fetal sex determination at earlier stages in pregnancy, such as amniocentesis, chorionic villus sampling, and blood tests, are largely unavailable. This limitation has one very important implication: for the vast majority of women in Pakistan, it is not possible to have a sex-selective abortion in the first trimester.

One final question remains: To achieve the desired sex ratio among their children, would Pakistani couples be willing to resort to the extreme step of abortion? The evidence indicates they might be. Over the past decade, studies have confirmed a high incidence of induced abortions in the country, notwithstanding religious censure, cultural stigma and a law against abortion. In 2004, one out of every six pregnancies was estimated to be terminated by an induced abortion (Population Council 2004), and abortion incidence has risen significantly since then (Sathar et al. 2013). This readiness of couples to resort to abortion to terminate unwanted pregnancies, combined with the confluence of son preference, declining fertility, and increasing access to and advancement of fetal sex determination technology, implies that Pakistan may at some stage, if not already, be faced with the challenge of prenatal sex selection and the associated SRB distortions.

The above observations also imply that the risk of prenatal sex selection is likely to be highest among urban and educated communities where the fertility transition is more advanced and there is greater access to knowledge and services enabling prenatal sex selection. Karachi, the country's largest metropolis, fits these criteria well. With a population of 15 million and slightly elevated SRB of 107.5, the port city boasts higher educational attainment-about 40 percent of women having secondary or higher education; a contraceptive prevalence rate of $45 \%$, which is well above the national average; and a nearreplacement total fertility rate of 2.6, according to the Pakistan Social and Living Standards Measurement Survey (PSLM), 2012-13. Access to health services, including antenatal ultrasound services, is high. Moreover, as a hub of industrial activity and international trade, and the largest urban market in the country, Karachi leads the way in the introduction and uptake of new technologies; the more sophisticated means of early fetal sex detection that are not currently available in most of Pakistan are most likely to be pioneered here. These characteristics make Karachi a suitable site for exploring the presence of sex selection trends. 


\section{Study Objectives}

This study by the Pakistan office of the Population Council consisted of an extensive literature review followed by an exploratory qualitative study in Karachi to obtain the perceptions of reproductive healthcare providers regarding the demand- and supply-side practices that might indicate the occurrence or risk of prenatal sex selection.

The specific objectives of the study were to gauge the prevalence and impact of son preference, the use of ultrasound technology to identify the sex of the fetus, and incidence of abortion in general and sexselective abortion in particular, as well as to take stock of efforts by the state and other stakeholders to preempt such practices by enforcing the law on abortion, sensitizing healthcare providers to the risks, and elevating the position of daughters in society. Both the qualitative study and the literature review also focused on identifying strategies to counter the risk and/or occurrence of sex-selective abortions.

\section{Structure of the Report}

The background, rationale and objectives of the study have been discussed in Section 1 of this report. Section 2 outlines the methodology adopted to conduct the literature review and qualitative study. Section 3 presents the findings of both study components concerning (1) the existence of son preference; (2) patient and provider practices surrounding fetal sex detection and disclosure; (3) abortion in Pakistan, including the relevant law and its enforcement, and incidence of abortions in general and sex-selective abortion in particular; and (4) ongoing as well as recommended efforts to counter the risk of prenatal sex selection. Key findings and conclusions of the study are presented in Section 4. 


\section{SECTION 2}

\section{METHODOLOGY}

The design for this study of son preference and prenatal sex selection included two complementary components: a literature review and a qualitative study of perspectives of reproductive healthcare providers in Karachi. The methodology adopted for the two components is outlined below.

\section{Literature Review}

The literature on Pakistan reviewed for this study focused on the prevalent culture of son preference and daughter neglect, and the impact of these on the survival of male and female children; the effect of son preference on fertility preferences, trends and decision-making; legislation on abortion in Pakistan; and evidence concerning abortions, including sex-selective abortions. Data from past censuses and sample surveys was compared. Government and other social sector interventions aimed at preventing exacerbation of gender biases and promoting and protecting female rights and empowerment were examined to determine the extent of policies targeting this issue.

Extensive use was made of online search engines including Jstor, Google Scholar, and Science Direct. Specific terms used in these searches included "son preference," "sex selection," "sex ratios," "ultrasound use," "abortion," "female empowerment," and "Pakistan." Various combinations of these keywords and terms were used for optimal results. The repository of relevant journal articles developed exponentially, with bibliographies within material used leading to other sources and research papers. Material and data was also accessed through the websites of the Population Council, the World Health Organization, World Bank and the United Nations Population Fund (UNFPA). The Pakistan Demographic and Health Surveys and the national censuses were also large sources of information.

A complete list of the sources consulted is presented at the end of this report.

\section{Qualitative Study}

The qualitative study was conducted in Karachi, Sindh, and consisted of in-depth interviews with a purposively selected sample of key informants who represented different tiers of reproductive healthcare providers in the public and private sectors. 


\section{Study Site}

As discussed earlier, the city of Karachi was selected for the study because, compared to the rest of the country, its population is more advanced in its fertility transition; more urbanized and educated; and has greater access to basic facilities, including antenatal healthcare and use of ultrasound services, as well as cutting-edge technologies. These factors are linked with a greater risk of prenatal sex selection by Guilmoto (2009), and associated with a higher chance of skewed sex ratios at birth according to the results of PDHS 2012-13. At present, the city's sex ratio at birth, estimated by PSLMS 2012-13 at 107.5, is only marginally beyond the normal range of 102 to 107 , but it is relatively higher than the national average of 102.5 and urban average of 103.9 reported by PDHS 2012-13.

A profile of the city is presented in Table 4.

Table 4: Profile of Karachi - 2012-2013

Urban Population (\%)

Rural population (\%)

Average household size

Net enrollment rate (Primary) overall

62

Male

Female

Net enrollment rate (Middle) overall

Male

Female

Net enrollment rate (High) overall

Male

Female

Literacy-population 10 years and older overall

Male

Female

Percent of Households with tap water as source of drinking

Percent of Households using a flush toilet

Current use of contraception, female (Any Method)*

Current use of contraception, female (Modern Method)* 


\section{Study Sample}

Since the qualitative study was intended to be exploratory and focused specifically on the city of Karachi, it was based on a small sample size of 15 key informants. The informants were selected through purposive sampling for interviews in Karachi. They included qualified and experienced female service providers of different levels, i.e., gynaecologists, lady doctors, sonologists and Lady Health Visitors (LHVs)/nurses, representing both the public and private sector and serving both high and low socioeconomic groups of the population.

To ensure that the sample included providers who would be knowledgeable about the issue of sexselection abortions, a list of possible informants of different levels was first drawn up through discussions with senior healthcare providers in Karachi. From the list, informants were selected with a view to representing all key types of services (gynecology, sonology, nursing, etc.) as well as both the public and the private sectors. The providers selected in this manner were mostly found to be catering to clients in the higher and middle income groups. To ensure that the perceptions of providers serving low socioeconomic areas were also included in the study, a few respondents were identified by personally visiting such localities of Karachi and finding out from medical stores and pharmacies about female providers managing gynecological or maternity practices or ultrasound clinics in the area. Details about the 15 key informants selected are provided in Table 5.

Table 5: Characteristics of Providers Interviewed

\begin{tabular}{lc}
\hline Type of Providers & Number of Providers \\
\hline Gynaecologist & 7 \\
Sonologist & 3 \\
General Doctors & 3 \\
LHV/Nurse & 2 \\
Total & 15 \\
\hline Age & Number of Providers \\
\hline $30-39$ years & 1 \\
$40-49$ years & 2 \\
$50-59$ years & 7 \\
$60-69$ years & 3 \\
$70+$ years & 2 \\
Total & 15 \\
\hline Qualification & Number of Providers \\
FRCOG/FCPS & 7 \\
MCPS & 3 \\
MBBS & 3 \\
LHV/Nurse & 2 \\
Total & 15 \\
\hline Experience & Number of Providers \\
\hline $11-20$ years & 2 \\
$31-40$ years & 5 \\
$41+$ years & 6 \\
Total & 2 \\
\hline
\end{tabular}




\section{Data Collection and Processing}

Interviews for the study were conducted from November 24 to December 14, 2014 by a senior researcher at the Population Council. A structured guide was used for the in-depth, face-to-face interviews with key informants. The questions asked concerned the respondents' perception of son preference among the clients they came in contact with; the demand for fetal sex disclosure and providers' responses; incidence of sex-selective abortion; enforcement of the abortion law against those who provided such services; any programs respondents were aware of aimed at sensitizing health professionals to sex-selective abortion; and their views on what measures should be taken to curb the incidence and/or risk of sex-selective abortions in Pakistan.

The data collected through the interviews was digitally recorded and the discussions transcribed and stored in mp3 file format along with the respondent face sheet. All the data collected was kept confidential. The questionnaires were identified by personal identification numbers instead of participants' names to preserve anonymity. After a thorough content review, codes and themes were finalized and matrices developed. The data was sorted on the basis of themes and subthemes and subsequently analyzed.

\section{Ethical Guidelines}

The Population Council requires all studies involving human subjects to be reviewed by its Institutional Review Board (IRB) before an activity is initiated; accordingly, ethical approval from the IRB was obtained for the study.

Informed consent from the respondents was obtained after providing an in-depth briefing on the study, its objectives, procedures and uses. The approximate time required for the interview was also explained. An assurance was provided to the respondents about the anonymity and confidentiality of their responses. Privacy was maintained throughout the interviews. Respondents were informed that their participation was voluntary and that they may refuse to answer any question that made them uncomfortable or terminate the interview at any time.

As mentioned above, all data collected for the study was kept confidential and stored securely, without identifiers of individuals. 


\section{SECTION 3}

\section{FINDINGS}

This section presents the findings of the study regarding the prevalence of son preference; fetal sex disclosure; the abortion law and its enforcement; abortion incidence, with a focus on sex-selective abortion; current social sector and health interventions to counter the risk of sex-selective abortions; and further measures that may be taken in this regard.

The following discussion integrates the findings of the literature review and the qualitative study of healthcare provider perspectives.

\section{Prevalence of Son Preference}

\section{Main findings:}

Healthcare providers in Karachi confirm the findings of studies that son preference is widely prevalent in Pakistani society. Sons are preferred because they are seen to confer social value upon their family, carry the family name, inherit, and can shoulder economic responsibility.

The desire for more sons causes couples to delay contraceptive use even when they have a large number of daughters.

Some providers perceive son preference to be lower in the higher socioeconomic class, among educated families, and in some communities, such as Urdu speaking and Punjabi communities (as compared to Pathan and Baloch communities).

Successive studies and household surveys have found rich evidence of preference for sons among Pakistani families, which has been presented in the introduction to this study. So entrenched is this preference that it translates into differential treatment of boys and girls by their own parents, resulting in poorer nutritional, health and educational care of girls and leading to disproportionately higher mortality among them than boys.

To a great extent, the findings of the literature review regarding the prevalence of son preference in Pakistani society are supported by the findings of the qualitative study in Karachi. When the interviewed 
healthcare providers were asked whether they thought parents generally preferred sons, most agreed that sons were preferred by families in Karachi as well as in Pakistan in general.

The respondents were then asked to give examples of any behavior they had observed among their patients or their families that indicated they preferred to have sons. There was a unanimous response that women were happy and their faces lit up when they heard that the fetus was male. In lower classes, mothers were treated better by their families when they were carrying a male baby: they were provided special care, good nutrition and rest.

One the other hand, when they were informed the fetus was female, a respondent reported women asked that the ultrasound be repeated to make sure. If they already had two or three daughters, they sometimes started crying. The unhappiness and depression was attributed by respondents to pressure from in-laws and relatives who are displeased and behave poorly with women when they conceive a girl. It was mentioned that sometimes women are even divorced for bearing daughters.

People react differently at the birth of a boy or a girl. When they get the news of a third or fourth baby boy, they are happy, but if it is a girl, then they become sad. I have seen two to three cases going in depression and post-partum hemorrhage. (Female, Lady Health Visitor, aged 36).

A woman came to me for a checkup and ultrasound. She already had three daughters and now again she had a female child. On hearing this, she started crying and said not to inform her in-laws about it because they would be angry and mistreat her. (Female, Gynaecologist, aged 58).

When they were asked why they felt there was such strong son preference, providers gave multiple reasons, including families' desire to carry on the family name; inheritance issues; parents' expectation of sons' support in old age; the perception that sons require less care than daughters, owing to the latter's greater social vulnerability; the family prestige and value associated with sons; the financial burden entailed in daughters' marriages, particularly in the form of dowry; and the distress and problems that can be caused for parents by their daughters' in-laws.

Everyone wants a son. It is a [mark of] social status for a woman. She is given respect after the delivery of the son by the family and the community. (Female, Gynaecologist, aged 58).

There are multiple reasons, mainly socio-cultural, carrying over family name, inheritance problem, sons will look after the family in late life, girls will not repay rather they give more financial burden. (Female, Gynaecologist, aged 52).

Sons are preferred to run the family name, for inheritance. They give value to family and help in old age. (Female, Nurse, aged 42). 
However, two respondents said that son preference does not have a strong hold on society, especially in the high socioeconomic class. Parents are happy to have a son but they do not care much either way; they treat baby boys and girls the same way. One respondent even mentioned that mothers wanted to have at least one daughter because they are seen to be closer to their parents than sons.

Minds have changed now and I have not seen much preference for a son. (Female, sonologist, aged 70).

I don't agree with the statement that there is a son preference. I have noticed that mothers want at least one daughter as they are very close to their mothers while in our culture now sons are less caring. (Female, Doctor, aged 48).

Moreover, one of the respondents (Female, Gynaecologist, aged 50) referred to communal differences in son preference, pointing out that son preference was more pronounced among Pathan and Balochi communities settled in Karachi, "as they did not value women," in comparison to Punjabi and Urduspeaking families.

\section{Effect of Son Preference on Fertility Preferences and Behavior}

A number of studies have found that son preference exerts a clear influence on fertility preferences and behavior in Pakistan. In 2006-07, 65 percent of women with three sons wanted to have no more children, compared to only 14 percent of those with three daughters (PDHS 2006-07). Zaidi (2013) found that stagnating contraceptive use rates in Pakistan, as indicated by the PDHS 2006-07, were an outcome of women continuing to have more children to produce sons. This gender consideration in the decision to have another child appears to have persisted. According to the most recent cohort study evaluated the role of the sex of children on reproductive intentions and subsequent behavior of women in urban slums of Karachi, Pakistan (Hussain, Fikree, \& Berendes 2000). According to its results, pregnancies become increasingly unwanted as the number of surviving sons increases. The sex of surviving children is also strongly correlated with subsequent fertility and contraceptive behavior. At higher parity levels, women with three or more surviving sons and no or only one surviving daughter are more likely to report their pregnancy as unwanted compared to those women who have three or more daughters and none or one surviving son. The results show that, when effect of marriage duration is controlled for, the sex of the surviving children is the main explanatory variable for the unwantedness of a pregnancy. Specifically, with every increase in the number of surviving sons, a woman is two and a half times more likely to report her pregnancy as unwanted. Additional fertility becomes more closely associated with the surviving number of sons beyond parity level two.

The study also finds the sex of surviving children to impact use of contraception: at second parity, 14 percent of women with two surviving daughters and no son stated they were using contraception, compared to 43 percent of women with two surviving sons and no daughter (Hussain, Fikree, \& Berendes 2000).

This gender consideration in the decision to have another child is also evident from the results of the Pakistan Demographic and Health Surveys. In 2006-07, 65 percent of women with three sons wanted to 
have no more children, compared to only 14 percent of those with three daughters (PDHS 2006-07). Currently, 60 percent of women with three sons want to have no more children, compared to only 21 percent of women who have three daughters (PDHS 2012-13). Similarly, among women with five children, about 90 percent of those with two to four sons said they wanted no more children as compared with 73 percent of those with no sons or only one son (PDHS 2012-13). The relationship between the desire for additional fertility and number and sex of living children is illustrated in Figure 3.

\section{Figure 3: Desire for more children by sex of living children}

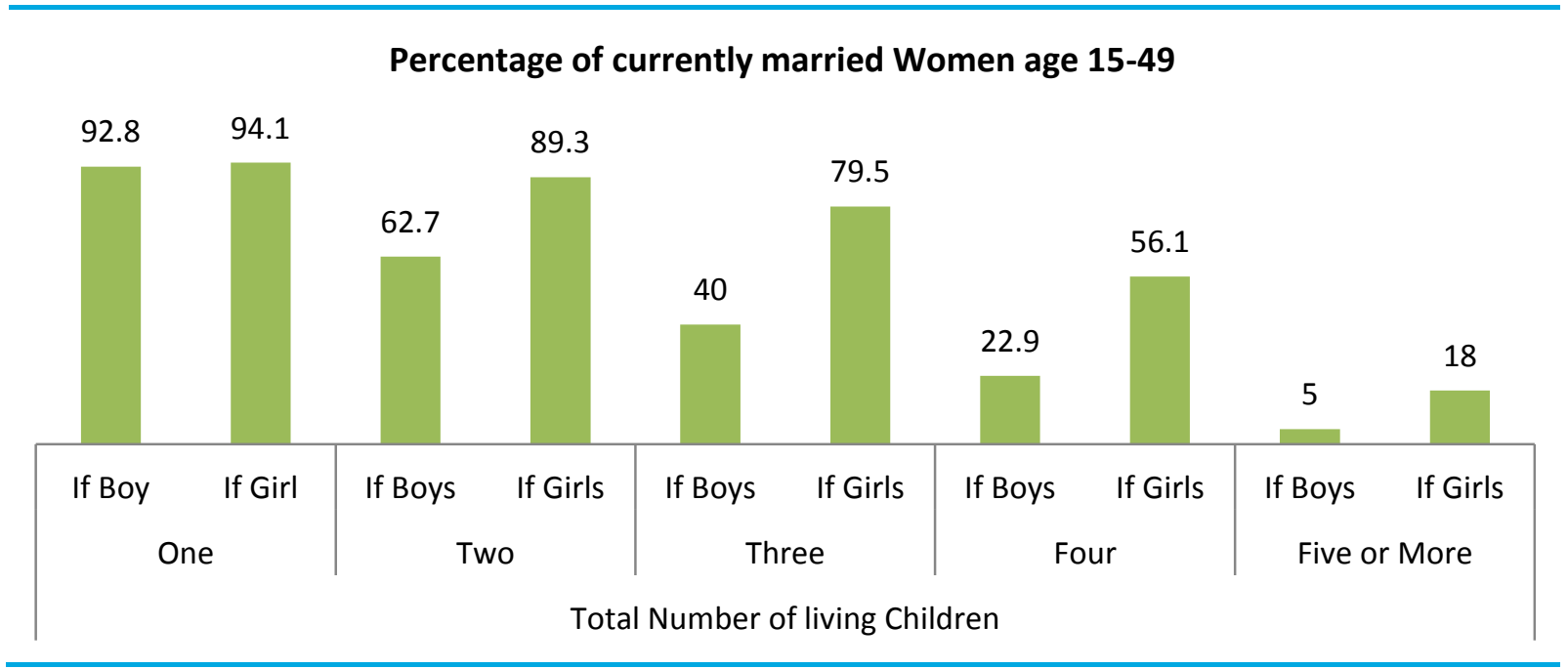

Source: PDHS 2012-13

The above findings bear out the prediction of Mahmood and Ringheim (1996) that "early contraceptive adopters are likely to be those of relatively high parity who believe they have a sufficient number of sons. Given the low level of contraceptive use among women, our expectation is that the impact of the number of living sons on contraceptive use will be relatively small, but will be greater than that of living daughters."

The above findings of the literature review are largely supported by the qualitative study. Healthcare providers interviewed agreed that women with a large number of daughters can defer family planning, sometimes at the risk of their lives, in hopes of having a son.

A woman came to me for treatment of secondary infertility. She already had seven daughters but due to her desire for a son, she wanted the treatment and said after that she would adopt family planning. (Female, Gynaecologist, aged 50).

Recently, a woman [came who] had serious medical problems and four daughters, all by caesarian sections. On the fifth pregnancy, she again had a baby girl but she refused to have sterilization and took another chance, putting her life at risk, to have a son. (Female, Gynaecologist, aged 52). 
It could be argued that, in opting to continue to have children when they have daughters and to restrict further fertility when they have sons, couples engage in an indirect form of sex selection. However, it is beyond the scope of this study to explore the effect of such 'sex-selective fertility limitation' on family sex ratios.

Notably, even in the presence of pervasive son preference, the desire for another son is not a constant and can in some situations be replaced by a desire for daughters or even indifference as to the gender of the child. PDHS 2012-13 found the proportion of women who wanted no more children dropped from 90 percent among women with two to four sons to 76 percent among women with five sons and no daughters, probably due to a desire for at least one daughter. Similarly, Royan and Zaidi (2011) find that more than two-thirds of childless women do not have a sex preference for their first child, perhaps due to cultural pressures to prove their fertility as opposed to producing a son.

The current qualitative study identified similar exceptions, with several respondents pointing out that gender preference depends on the sex of children couples already have.

I had two patients one with four children who were all boys and the fifth was also a boy but she wanted to take a chance for a girl. The second patient had previously three baby girls and the mother wanted to take a fourth chance for a baby boy. Knowing the sex beforehand makes them mentally prepared and they do not lapse into depression. (Female, Gynaecologist, aged 56).

There was one couple who had six girls and again the seventh was also a girl. They decided to give up the child for adoption. After the delivery, they gave the baby to their relatives who had six boys and wanted a girl. (Female, Nurse, aged 42).

It depends on what gender they previously have; 80 percent people prefer to have a son as a first child. In the higher class, they don't bother. (Female, Gynaecologist, aged 56).

\section{Effect of Education, Wealth and Region on Son Preference}

Findings from PDHS 2012-13 suggest that son preference persists in Pakistani society across different levels of education and wealth, as well as across all four provinces. The figures provided in Table 6 indicate that while desired fertility does vary with education, income level and region-being lower among women who are educated, in the middle and high income groups, and living in Punjab-the proportion of women preferring three or more sons remains two to three times higher than that of women who desire as many daughters in all categories. 
Table 6: Child Gender Preference among Ever Married Women by Education, Wealth and Region

\begin{tabular}{lcc}
\hline & Women who want 3 or more sons, \% & Women who want 3 or more daughters, \% \\
\hline Education & 47 & 21 \\
No education & 11 & 4 \\
Higher education & & 25 \\
Income Group & 57 & 15 \\
Low & 34 & 8 \\
Middle & 16 & 10 \\
High & & 19 \\
Province & 20 & 11 \\
Punjab & 35 & 33 \\
Sindh & 35 & \\
Khyber Pakhtunkhwa & 60 & \\
Baluchistan & & \\
\hline
\end{tabular}

Source: PDHS 2012-13

Interestingly, however, a significant proportion of the health providers interviewed for the qualitative study were of the view that higher socioeconomic class and more education were associated with reduced son preference. This perception was expressed most clearly when the healthcare providers were asked whether the trend of son preference had remained constant, weakened or strengthened in Karachi and among younger couples over the last few years. Six of the fifteen respondents felt that son preference was declining because people are more educated and realize the value of girls; women are doing everything equally with men, while taking greater care of their parents; and because social norms have changed with the passage of time. Indeed, two respondents categorically stated that son preference is weakening even in middle and lower socioeconomic groups because of increasing education of girls.

Because of education of girls, son preference has come down, now people know the value of females, and they don't care much about the gender. (Female, Sonologist, aged 70).

It is almost same in lower class but in upper class and educated people, son preference is coming down. (Female, Gynaecologist, aged 50).

It is weakening even in lower and middle class because of education of girls. (Female, Doctor, aged 48).

These responses indicate that while education and higher socioeconomic class increase the likelihood that women will pursue their desire to select the gender of their children-as found by Fatmi and Avan (2002), Fikree and Pasha (2004), Royan and Zaidi (2011)-they simultaneously work against sex selection through reduced desire for sons.

It needs to be borne in mind, however, that the majority of respondents did not perceive any decline in son preference, with five stating it had remained constant over the years and four feeling it had grown stronger, mainly in the Pathan segment of the population. 


\title{
Fetal Sex Detection and Disclosure
}

\author{
Main Findings: \\ Ultrasound technology is widely used in Pakistan as part of antenatal care. This technology cannot detect the sex of \\ the fetus before 18 weeks of gestation. \\ There is no law against fetal sex disclosure. \\ Most parents ask to know about the sex of the fetus, and this demand is unaffected by education or socioeconomic \\ status. \\ The demand is attributed by healthcare providers to parents' desire to be prepared with appropriate names, clothes, \\ etc. Desire to abort female fetuses is not mentioned as a reason. \\ Most providers inform parents about the sex of the fetus and do not consider this a harmful practice. \\ A few healthcare providers refuse to disclose the sex of the fetus because they believe it is religiously impermissible to \\ have or impart knowledge of the sex of an unborn child. Some health facilities also maintain a policy of non- \\ disclosure because the ultrasound result may be wrong, which can lead to disappointment and anger among clients \\ and reluctance to own the child.
}

For son preference to translate into skewed sex ratios at birth, parents need to have access to fetal sex detection technology as well as abortion services. This section looks at the first of these requirements, i.e., the parent and provider practices surrounding usage of technology that can detect the sex of the fetus. Abortion services and their use are covered in the next section.

\section{Availability and Usage of Fetal Sex Detection Technology}

The only evidence of use of sex-detection technology in Pakistan pertains to the use of ultrasound checks during pregnancy, which is documented in the Pakistan Demographic and Health Surveys. There is no law in the country against divulgence of the gender of the fetus following an ultrasound. According to PDHS $2013,88.7$ percent of women (including $94.1 \%$ of urban and $86 \%$ of rural women) had an ultrasound done during their most recent pregnancy, showing that ultrasound technology is widely available in both urban and rural areas of Pakistan.

It is not clear whether these ultrasounds were conducted for fetal health monitoring or to identify the gender of the fetus, and whether they were conducted at a stage when the sex of the fetus could be determined. However, it is very important to note that the ultrasound technology used in the country cannot reliably detect the sex of the fetus before 18 to 20 weeks of pregnancy. Availability of the more advanced diagnostic technologies that enable fetal sex determination at earlier stages in pregnancy, such as amniocentesis, chorionic villus sampling, and blood tests, is severely limited in the country. Even in Karachi, the country's most advanced metropolis, only one or two private sector tertiary facilities offer these services.

Owing to the extremely limited availability and high expense of these services, it may safely be assumed that access to fetal sex detection services in the first trimester of pregnancy is negligible. Therefore, if sexselective abortions were to occur in Karachi or elsewhere in the country, they would take place after the eighteenth week of gestation, which is the earliest possible stage at which available ultrasound technology can identify the sex of the fetus. 


\section{Parents" Demand for Fetal Sex Disclosure}

To assess the interest of parents in identifying the sex of the fetus, respondents in the qualitative study were asked whether the women they were serving or their families ever requested that they reveal the sex of the fetus. The majority replied that most parents asked about the gender of the baby, and this was the case across all socioeconomic groups, and among educated as well as uneducated people. However, one gynaecologist said that not all women ask because many feel that seeking to know the sex of the baby in advance is religiously prohibited. A doctor explained that educated people knew from the Internet that it was possible to know about the gender of the fetus in advance and argued if they were not informed.

Most of the educated people come with full knowledge taken from the Internet and if we don't tell them, they argue. (Female, Doctor, aged 50).

When asked what percentage of pregnant women asked service providers to tell them the gender of the fetus, nine out of the fifteen respondents replied more than $80 \%$, five felt the proportion was $50-70 \%$, and only one respondent thought that merely $30 \%$ of women want to know about the gender of the fetus. Combined with the PDHS 2012-13 finding that $94.1 \%$ of urban women had an ultrasound done during their most recent pregnancy, this suggests that the vast majority of pregnant women in Karachi are interested in finding out the sex of the fetus.

This interest appears to be maintained across all income levels as the majority of the respondents (twelve out of fifteen) said women and families from all socioeconomic groups ask about the sex of the fetus. However, one respondent added that although everyone asked, those from low socioeconomic groups were more concerned. On the other hand, a sonologist who had two clinics, one in a low socioeconomic group area and the other in a high socioeconomic group area, said that women of the high-income group ask more about the sex of the fetus compared to those from the low economic group.

One of the sonologists interviewed who had her own clinic had a notice posted at the entrance saying that the facility did not disclose the sex of the fetus to clients. According to her, in 15 years, only one couple had left the facility without having an ultrasound done as the woman had come only to learn about the sex of the fetus. This suggests that desire to know the sex of the fetus is not the only reason for most parents' use of ultrasound services.

When asked how they felt the demand for fetal sex disclosure in Karachi compared with demand in other areas, the majority of respondents (nine out of fifteen) said that it is more common for women to ask about the sex of the fetus in other areas, especially in rural areas, than in Karachi. On the other hand, two respondents said demand was greater in Karachi, while two said demand was the same all over Pakistan. The remaining two providers said they could not respond to the question as they had no knowledge about the situation in other areas.

Respondents were also asked whether they felt the tendency among clients to demand disclosure of the sex of the fetus had increased, decreased or remained constant. All the respondents held that the demand for disclosure of sex of the fetus had increased. They gave a number of reasons for this, including the following: 
- $\quad$ People are more aware that laboratory tests can detect the sex of the fetus;

- $\quad$ Access to test facilities has increased;

- $\quad$ Birth preparedness has become a norm in society; and

- Mainly, people want to prepare for the babies, e.g., select their names, prepare clothes and set up their rooms, etc.

Technology has improved and providers are more confident so they tell the sex of the fetus. (Female, Gynaecologist, aged 52).

People have become aware and they insist [on knowing the sex of the child] for prebirth preparations of clothes. (Female, Nurse, aged 42).

None of the respondents listed interest in sex-selective abortion or even having a gender-balanced group of children as possible reasons for families' wanting to know the sex of the fetus. This suggests that sexselective abortion is not perceived to be a common practice by providers and their clients.

\section{The Supply Side - Providers' Response to Client Requests for Disclosure}

As mentioned earlier, there is no law in Pakistan prohibiting the disclosure of the sex of the fetus to pregnant women or their families, and providers may do so, if they wish. When asked how providers respond to requests for disclosure of the sex of the fetus-i.e., whether they provide or withhold the information-eleven respondents responded that most providers of all levels comply with the request.

When asked whether any special category of providers were more likely to disclose the sex of the fetus, respondents gave a mixed response. Some said gynaecologists who did ultrasounds were more likely to disclose the sex, while others said sonologists had a higher tendency. Still others said that providers of all levels were willing to disclose the sex of the fetus. Most respondents were of the opinion that providers working in small maternity homes and mid-level providers were more likely to comply with requests for disclosure.

For the most part, the interviewed providers felt there was no harm in informing parents about the sex of the fetus.

We inform them if they ask but we counsel them against termination if they intend it. (Female, Nurse, aged 42).

I don't think there is any harm in telling the sex. Now there is so much modernization that we cannot hide it. If the gynaecologist refuses to disclose, then the sonologist will tell them. (Female, Gynaecologist, aged 52).

All providers tell the sex of the fetus if the patient asks. (Female, Doctor, aged 60). 
However, one respondent was of the view that the gender of the fetus should not be disclosed, even if women ask, because there is a chance of misinterpretation of the ultrasound result, which can cause disappointment later. ${ }^{3}$

Most of the women do ask but it should not be disclosed because if on ultrasound it is wrongly interpreted then it creates issues later and parents do not own the child happily. (Female, Gynaecologist, aged 50).

Perhaps for this reason, a few gynaecologists said that in some tertiary care hospitals, both in the public and the private sector, there is a general policy that the gender of the fetus should not be disclosed to families.

Two respondents also said that they knew a few providers who do not disclose the sex of the fetus because this is against their code of ethics and religious beliefs: they believe it is wrong to seek knowledge of the sex of a child to be born. One respondent said that doctors with strong religious beliefs do not disclose the sex of the fetus to their clients but others do.

Respondents were asked to indicate the proportion of providers who generally comply with requests to disclose the sex of the fetus. The majority of respondents said that $70-80 \%$ of providers inform women or their families about the sex of the baby, while three opined that only $50-60 \%$ of providers do so.

When asked how fetal sex disclosure in Karachi compared with other areas, about half of the respondents said it was higher in Karachi due to greater awareness and availability of health facilities, while three were of the view that the level of disclosure was the same as in other areas. Only one provider said disclosure was lower in Karachi than other areas, while two did not respond to the question as they had not worked in other areas.

Respondents were also asked whether they felt fetal sex disclosure had increased, decreased or remained constant over the preceding ten years. They were unanimous in the view that it had increased. The main reasons given were that technology and equipment quality has improved, and doctors are more confident about the accuracy of reports. Moreover, patient interest has increased due to greater awareness, and there is increased demand for pre-birth preparation of clothes, rooms, etc.

\footnotetext{
3 Anecdotal evidence indicates that this disappointment frequently turns to anger against healthcare providers, especially among less educated families: when relatives of a woman who has been told she is expecting a son are informed of the birth of a daughter, they can accuse providers of foul play and create disturbance at the facility.
} 


\title{
Incidence of Sex-Selective Abortion
}

\author{
Main Findings: \\ By law, abortion is permitted before the fourth month of gestation if continued pregnancy threatens the mother's life \\ or "necessary treatment" is required. After the fourth month of gestation, abortion is permitted only if the pregnancy \\ threatens the mother's life. \\ The law is not perceived to be enforced by healthcare providers in Karachi, and most healthcare providers are not \\ aware of its key provisions. \\ Induced abortions are conducted only in the private sector in Pakistan. \\ Abortion incidence is high: an estimated 2.2 million abortions were performed in 2012. Women's main reasons for \\ abortion include birth spacing and limiting, as well as poor maternal health. \\ According to healthcare providers, most abortions are conducted in the first trimester, when the procedure is easier \\ to perform. At this stage, the sex of the fetus cannot be detected by available ultrasound technology. \\ Limited and mostly only informal and indirect evidence is available for incidence of sex-selective abortion in \\ Pakistan.
}

Healthcare providers interviewed in Karachi are strongly of the opinion that sex-selective abortions are not taking place. In their view, even where a woman intends to abort a female fetus, she is unable to do so because the sex of the fetus cannot be determined before 18 weeks, and abortion becomes far more difficult to carry out at that point.

The desire to abort female fetuses does exist in specific cases. Fear of another female birth can drive women to abort fetuses without confirming whether they are male or female.

As the foregoing sections have indicated, son preference persists among couples in Pakistan and is strong enough to affect their fertility decision-making. Moreover, most pregnant women get an ultrasound during pregnancy, during which they ask what the sex of their fetus is, and in most cases, the provider complies with their request to know. The main questions that remain to be answered are whether women, upon finding they are expecting a daughter, are in a position to have an induced abortion, and whether they do in fact take this step. In this regard, following section discusses the effectiveness of legislation pertaining to abortion in Pakistan; the incidence of abortion in the country; and evidence of abortions driven by the intent to select the sex of children.

\section{The Abortion Law, Its Enforcement and Provider Awareness}

Abortion was originally a subject of the Penal Code of 1860 , which was developed for India by the British colonial government and continued to be applicable after Pakistan's independence. In 1989, the country's Supreme Court passed a new law on abortion, which was, however, found to be repugnant to the injunctions of Islam. A revised law came into effect in 1990 and became permanent in 1997. Under the current law, abortion offenses are divided into two categories depending upon whether or not the 
organs of the fetus have formed. ${ }^{4}$ Abortions carried out before the fetus has formed organs are permitted when performed to save the mother's life or to provide "necessary treatment" (which is not clearly defined). After the fetus has formed organs, abortions are only permitted if the mother's life is threatened. The precise penalties for illegal abortion depend on the fetus's developmental stage. Providers who conduct illegal abortions may be imprisoned for up to three years, if the woman consented, and ten years, if she did not (UN Population Division 2002).

In the interviews conducted during this study, healthcare providers were asked whether the law is adequately enforced in Karachi. All of them were of the opinion that there is no specific authority responsible for enforcing the law for abortion in Pakistan, there is no monitoring mechanism at all, and no action has ever been taken against any provider for performing an illegal abortion. They were also unanimously of the view that no nongovernmental organizations (NGOs) or advocates were working on this issue in Karachi.

The majority of providers held that authorities turn a blind eye to this issue, and there is a general spirit of not caring what the law says or what is happening in society.

Authorities completely turn a blind eye as there are some NGOs working in collaboration with the government and are performing abortions. (Female, Gynaecologist, aged 56).

There are no law enforcement agencies [to monitor or check illegal abortions]. I have not heard of any doctor going to jail for doing an abortion, now was any women sent to jail for having an abortion. (Female, Sonologist, aged 70).

I remember a case of [a woman who died of] multi-organ failure due to complications in an induced abortion, but no litigation was undertaken. (Female, Doctor, aged 50).

The respondents were also asked if service providers were aware of the provisions of the abortion law in Pakistan, specifically those concerning the conditions and pregnancy stages in which abortion is permissible. Most replied that very few providers, mostly senior doctors working in tertiary hospitals, knew about the law. The majority of respondents, eleven out of fifteen, said that more than $80 \%$ of the providers did not have knowledge of the law, while four estimated that about $50-60 \%$ of providers are unaware of the law.

I think senior gynaecologists are aware of law but the junior doctors don't know about it. (Female, Gynaecologist, aged 56).

Providers working in tertiary hospitals may know about the law; other than that, very few providers are aware. (Female, Gynaecologist, aged 50).

No one knows the exact provisions of the law on abortion. (Female, Gynaecologist, aged 54).

\footnotetext{
4 Islamic scholars have usually considered the fetus's organs to have formed by the fourth month of gestation.
} 
Interestingly, when the respondents were asked what the abortion law stipulated, only two of the fifteen were aware of all of its provisions.

\section{Incidence of Abortions}

While care is readily provided for spontaneous and missed abortions within the public sector facilities, induced abortions are only conducted when the mother's life is threatened by continuation of the pregnancy or for necessary treatment. Post-abortion care, however, is part of the National Reproductive Health Package and includes pre- and post-abortion care (Population Council 2004).

However, many private clinics do offer induced abortion services illegally (Nosheen and Schellmann 2012), and a high prevalence of induced abortions was detected even a decade ago (Sathar, Singh and Fikree 2007). In 2002, there were an estimated 250,000 post abortion complications and 895,000 estimated induced abortions (Sathar, Singh and Fikree 2007). A national study by the Population Council (2004) found Pakistan's abortion ratio to be 20 per 100 births-in other words, one in six pregnancies in the country were being terminated by abortion. The study also identified variations in the abortion ratio across provinces and noted that the ratio was inversely proportional to the contraceptive prevalence rate (CPR). Four key reasons were given by women for opting to abort their babies: (1) they did not wish to have any more children; (2) they could not afford to have more children; (3) their last-born child was too young; or (4) they were concerned that their health would suffer (Population Council 2004). It is noteworthy that the sex of the child was not mentioned as a reason for aborting. A follow-up study (Sathar et al. 2013) sought to develop a profile of women seeking abortion services based on the views of experienced health professionals. It found that most of these women were aged 30 or above, married, with 5 or more children, poor and uneducated. It also found that the abortion rate had doubled over the preceding decade with about 2.2 million abortions being performed in 2012. The procedures were conducted under unsafe conditions by unskilled providers, and about 700,000 women visited health facilities for treatment of post-abortion complications.

During the interviews conducted under the current study, respondents were asked what proportion of pregnancy terminations occurring in Karachi were probably illegal abortions. It was difficult for respondents to answer this question accurately as they were themselves not aware of the actual law. Nevertheless, thirteen out of the fifteen respondents (those who did not have complete knowledge of the provisions of the law) said that $60-80 \%$ of abortions were probably being conducted against the law.

Notably, however, the two respondents who knew the law well were of the view that very few abortions, perhaps one out of ten, would be taking place against the law because the law allowed significant leverage and the majority of abortions were conducted within the first trimester of pregnancy. They also pointed out that, in the first trimester, sex-selective abortion would not be possible since available ultrasound technology cannot detect the sex of the fetus.

I would not call them illegal because they are being done in early pregnancy; so majority get aborted in first trimester so sex selection is not possible. (Female, Sonologist, aged 70). 
Very few abortions may be illegal because law has great leverage. (Female, Gynaecologist, aged 70).

\section{Evidence of Sex-Selective Abortion}

While abortions are being used to control fertility and tackle unwanted pregnancies, very little scientific evidence of sex-selective abortions is currently available (Zaidi 2013), and only a few indicators point towards this phenomenon. One of these is the aborting of a fetus before a couple's ideal family size is achieved. A study conducted on women hospitalized for post-abortion complications showed that 20 percent of women who had an abortion had 0-2 children, and another 30 percent had 3-4 children; however, the ideal family size was close to 4 children (Vlassoff et al. 2009, as in Zaidi 2013). This could suggest that the abortions might have been driven by gender preferences, although it was not explicitly stated. The indicator needs to be applied with caution, however, since other factors, such as last child being too young or the mother's health not being satisfactory at the time, can also operate in the decision to induce an abortion (Population Council 2004).

Other available evidence is indirect or informal. For example, Nosheen and Schellman (2012) find some informal evidence of sex-selective abortions in urban clinics in Pakistan, supported by Ghosh's (2013) claim that sex-selective abortions are accentuated amongst educated middle-class and upper-class women who have easy access to safe abortions.

A qualitative study by the Population Council found indirect evidence that the gender of existing children can play a role in the decision to seek an abortion (Population Council 2013). In focus group discussions, women stated that they terminated their pregnancies because they already had several daughters and were afraid they might have another one, but they did not confirm this fear with an ultrasound check. Of these forty-four women, only one had actually had an abortion on these grounds, and she had done so without determining the sex of the fetus through an ultrasound.

In the interviews with reproductive healthcare providers in Karachi, a number of direct and indirect questions were asked regarding the incidence of sex-selective abortions. Respondents were asked whether clients continued or terminated pregnancies upon finding out that the fetus was female. In response, fourteen out of the fifteen respondents were emphatic that nobody terminates a pregnancy because the baby is female.

I have not heard about termination of a pregnancy just because of female sex in Pakistan. (Female, Doctor, aged 48).

None, in my opinion, terminate because of female sex of the baby; usually they terminate the pregnancy due to contraceptive failure. (Female, Gynecologist, aged 52).

All women continue the pregnancy; no one tries to terminate the pregnancy because of a girl child. (Female, Gynaecologist, aged 54). 
However, one provider responded that, sometimes, women may terminate the pregnancy because of fear of family pressure following the birth of a girl. The following case was mentioned in this regard:

One woman came from Baluchistan secretly from her husband to abort her female fetus because the husband was absolutely against having a girl child. (Female, Lady Health Visitor, aged 36).

Respondents were asked to consider the illegal abortions that were being carried out in Karachi and give their view of what proportion of these abortions were being carried out for sex selection. Except for one respondent, who said that probably 10-20\% of abortions were conducted for sex selection, all respondents stated strongly that no sex-selective abortions were being conducted in Karachi.

Six providers pointed out that the sex of the fetus could not be determined until about 18-20 weeks on the ultrasound technology available. At this stage in the pregnancy, it becomes difficult to perform an abortion.

I usually tell them so late that they cannot not think of termination. I have not heard of any such case. (Female, Gynecologist, aged 52).

Till three months, the sex cannot be determined and then it becomes late for abortion. One woman wanted to know early but it is not possible. (Female, Nurse, aged 42).

Respondents were probed for their knowledge of abortion practices in the Karachi. When asked how clients terminate pregnancies if they decide to do so, only three providers were able to respond. Of these, two said the clients usually go to midwives or mid-level providers, while the third, a gynaecologist with 40 years of experience, said women now use Misoprostol to terminate a pregnancy. However, all three respondents were referring to termination of unwanted pregnancy in general, and not to sex-selective abortion

When asked whether abortion service providers are aware if the pregnancy is being terminated for gender selection reasons, one respondent said that service providers can sense this may be the case when husbands are highly inquisitive about the sex of the fetus. Thirteen respondents did not answer the question as they were unfamiliar with the situation.

Respondents were also asked whether the same provider performed both sex detection tests and abortion, or if there was any connection or nexus between providers who performed these two services. Most of the respondents said they had no knowledge about such practices (nexuses). Only three providers responded to the question. One said she had heard about such a nexus a few years ago but did not know the current situation. 
Yes, there are groups. I remember one case in which a doctor had given an ultrasound report of missed abortion at 12 weeks and then sent the patient for termination to a trained nurse of her own setup. (Female, Gynaecologist, aged 50).

Another respondent said that there were "setups" in the slum areas of Karachi for abortion of unwanted pregnancies but not specifically for sex selection. (Female, Lady Health Visitor, aged 36).

The question was asked what the general view of healthcare providers was regarding gender-biased sex selection. All respondents reported that providers are generally not in favor of sex-selective abortions, and hold that pregnancies should not be terminated unless there is a serious health issue. Moreover, when the respondents were asked whether people should be stopped from terminating pregnancies because the fetus is female, all of them held unanimously that no pregnancy should be terminated for this reason and the practice should be strongly condemned.

However, there was relatively less knowledge among respondents about the negative consequences of sex-selective abortions. The majority of respondents were of the opinion that providers are mostly unaware of this issue because it is not a major problem in Pakistani society and is therefore not given much importance. Nevertheless, when they were asked to speculate what the social implications might be if gender-biased sex selection took root in Pakistani society, eleven responded that this would lead to a lot of moral, ethical, religious and social problems because the population would be unbalanced and the social system would be disturbed.

If the women become less, population will go down as men cannot give birth. Women are sharing most of the responsibilities nowadays, and if they become less, [men's burden of] responsibilities will increase. (Female, Nurse, aged 42).

There would be drastic change because in this way it will be male dominant culture and females will not get their rights and property problems will occur. (Female, Lady Health Visitor, aged 36).

The same consequences will occur as in China, where now they are purchasing women from outside for marriages. (Female, Gynecologist, aged 50).

The providers were asked for their opinion about why the ratio of boys to girls was more unbalanced in Karachi than in other parts of the country. Interestingly, nearly all of them were unaware that such an imbalance existed. Even when they were informed that the sex ratio was in fact skewed, although they could not assign any reason for this, they specifically said that it could not be due to sex-selective abortion; some other normal phenomenon must underlie the situation.

I don't agree that there is any unbalance in the ratio of boys to girls in Karachi. Anyhow, even if it is so, it is not based on sex selection abortion, may be some other issue. Next PDHS surely will confirm this. (Female, Gynaecologist, aged 70). 
When asked whether they thought the sex ratios could normalize without taking any action, four healthcare providers said it was possible. One provider said:

I think it will come to normal because female survival is more than male so it will naturally become normal and if the quality of our neonatal units improves, the ratio will become normal. (Female, Sonologist, aged 70).

However, the remaining eleven providers did not respond to this question as they felt they did not have adequate knowledge about sex ratio distortions and underlying reasons.

\title{
Soclal, Health and Legislative Interventions to Prevent Sex Selection
}

\author{
Main findings: \\ Sex-selective abortion is not known to be a concern in Pakistan and no direct efforts to prevent it are under way. \\ Healthcare providers have not been sensitized to the possibility of prenatal sex selection. \\ Discrimination against girls and women is recognized as a serious issue. A National Policy for Development and \\ Empowerment of Women was introduced in 2002, followed by legislation to protect women's rights. A host of \\ nongovernmental efforts are under way to educate girls and ensure their adequate nutrition, and equip women with \\ skills for economic independence. \\ In other South Asian countries, activities identified to have scope for reducing sex selection include creative \\ advocacy, communication and community mobilization; women's employment, education and safety net programs; \\ conditional cash transfer schemes for girls; sensitization of healthcare providers; stronger regulation of use of fetal \\ sex detection technology; and better enforcement of improved laws. \\ Healthcare providers in Karachi do not believe sex-selective abortions are taking place on any significant scale. \\ Should the practice arise, most of them recommend: a program of behavior change communication that highlights the \\ religious prohibition as well as social fallout of sex-selective abortions; sensitization of healthcare providers; and \\ legislation to restrict fetal sex disclosure.
}

While prenatal sex selection is not known to be a concern in Pakistan, the gender bias faced by girls and women from birth onwards is recognized as a serious issue. A number of policy and programmatic steps aimed at female empowerment have been taken in the past decade that also serve to reduce and counter the effects of son preference, albeit indirectly. A sample of such efforts is provided below. Also outlined briefly are lessons emerging from the companion reports to this study (from India, Bangladesh and Nepal) concerning additional measures that work or hold potential to reverse sex selection. Finally, recommendations in this regard from the healthcare providers interviewed are presented. 


\section{Ongoing Efforts in Pakistan}

The National Policy for Development and Empowerment of Women (GoP 2002) represented the first clearcut government policy commitment to gender equality and the social, political, and economic empowerment of all women. Following this step, in 2004, the Ministry of Women Development was established as an independent ministry, and laws such as the Women's Protection Bill and Protection against the Harassment of Women at the Workplace Act have been passed.

In recent years, many programs have also been introduced in Pakistan that aim to empower women to counter the effects of gender bias through the provision of equal access to economic and educational opportunities as well as quality healthcare. While restoration of child and overall sex ratios is not a stated aim of any of these interventions, it is an indirect result since they are aimed at the root causes of the skewing of sex ratios.

Female labor force participation has a strong positive effect on sex ratios as women are considered to have more economic value once employed, giving parents less reason to prefer sons to daughters (Gechter 2010). Gechter (2010) suggests that when there is a fair chance of females being gainfully employed and bringing incomes home to their families, there is less reason for parents to prefer males over them. Thus, a lot of these interventions take the form of cash and non-cash transfer incentives for increasing girls' educational attainment, making them more economically independent, and increasing their value in society. For example, The Asia Foundation's Women's Empowerment Program recently completed an 18-month project focused on impoverished women in eight regions of Pakistan, training women to use new technologies and understand markets to help them be successful in business ventures. Traditional skills were enhanced and new technologies taught to help women break into maledominated fields. Business linkages were formed especially with microfinance institutions. Through the program, some 1,200 women were trained, 400 new businesses developed, and monthly incomes increased.

Many interventions target girls' education, which is essential for their economic and wider empowerment. A World Bank study (2013) found that gender-targeted conditional cash transfer enrollment programs were successful in increasing the enrollment of girls in classes 6 to 8 at school. To overcome the persistent low levels of school enrollment in the country, a stipend program for secondary school girls of Khyber Pakhtunkhwa was initiated in 2007 (SDPI 2013). The program was availed by 93 percent of households in the province, and it was estimated that 35 percent of girls would have dropped out of school if the stipend money had not been available. Similarly, the Punjab Female School Stipend Program (FSSP) is a targeted conditional cash transfer program implemented in Punjab in 2003 within the context of larger education sector reform and in response to gender gaps in education (IEG 2011). Four years after the program began, it was found that adolescent girls in stipend districts were more likely to progress through and complete middle school, and less likely to be drawn prematurely into work. There was also some evidence that suggested that girls who participated in the program would delay marriage by more than a year and have fewer births by the age of 19. The targeted districts were those with the lowest literacy rates. By 2007, 245,000 girls were covered by the program in middle school alone. Girls 
living in urban centers, in poorer households, and with more educated parents appear to be impacted the most by FSSP.

Among initiatives targeting the nutritional and health needs of girls, the Tawana project, a school nutrition package for rural girls, is noteworthy. An evaluation of the project by Badruddin et al. (2008) found a significant reduction in wasted, underweight and stunted young girls and an increase in enrollment at the schools targeted by the project.

Prenatal sex selection is not known to be an issue in Pakistan at present, and therefore no specific interventions to counter it were identified by this study, even in the health sector. The qualitative component of the study examined whether any programs were being conducted in the health sector to sensitize providers to the potential issue of sex-selective abortions, underlying reasons and implications. All fifteen respondents said they had neither heard of nor attended any such programs. One respondent said she had attended a discussion at an infertility clinic where the question of sex selection in in-vitro fertilization was raised, but the idea was strongly condemned.

However, the majority of respondents said that there should be programs to educate providers about the issue of sex-selective abortion, skewed sex ratios, and their implications.

\section{Lessons from Other South Asian Countries}

Experiences of other South Asian countries in countering distortions in SRB indicate that a combination of measures is required to reduce demand for sex selection on the one hand and regulate the supply of technology and services enabling sex selection on the other.

The companion report to this study from India finds advocacy, communication and community mobilization to be the most effective avenue for improving the SRB (Population Council, forthcoming a). The report draws attention to the success of practices such as counseling by frontline workers; involvement of religious leaders; and engagement of district officials with schools and village committees to raise awareness. The report recommends that communication campaigns highlight cases of "positive deviant families" where daughters have succeeded in taking care of themselves or their families, and emphasize the social fallout of sex selection in the longer run. The report also recommends that publicpartnerships of NGOs and authorities be forged in communication, advocacy and monitoring activities.

In addition, the companion report from Bangladesh recommends safety net programs for poor rural women as well as increased opportunities for subsidized education for girls and paid employment for women to enable them to substitute the economic role of men, and thereby address a core cause of son preference (Population Council, forthcoming $b$ ). Similarly, the companion report from Nepal recommends conditional cash transfer schemes for girls (Population Council, forthcoming $\mathrm{c}$ ). As indicated in the preceding section, such efforts are already under way in Pakistan.

Among supply-side measures, the companion reports recommend strengthening not only of laws against abortion and/or fetal sex disclosure but also of enforcement mechanisms; sensitization of medical 
practitioners regarding the social and legal implications of sex selection; and stricter regulation of the use of fetal sex detection technology.

Monitoring and research to assess the impact of interventions are also recommended.

\section{Providers' Recommendations for Countering the Risk of Sex-Selective}

\section{Abortions}

The healthcare providers interviewed in the qualitative component of this study were skeptical regarding the existence of skewed sex ratios at birth and sex-selective abortions in Karachi. Nevertheless, when they were asked what measures might help counter the risk of these phenomena, they offered a number of recommendations, several of which were surprisingly similar to the conclusions emerging from the experience of other South Asian countries.

\section{Social and Behavior Change Communication (SBCC) to Reduce Son Preference}

The majority of service providers-eleven out of fifteen-were of the view that the culture of son preference in Pakistan could be reduced by educating women and men, changing the mindset, empowering women, and reducing gender inequality. The need to educate both men and women was emphasized. Respondents held that men should be counseled about gender equality and encouraged to support women's empowerment as a religious obligation:

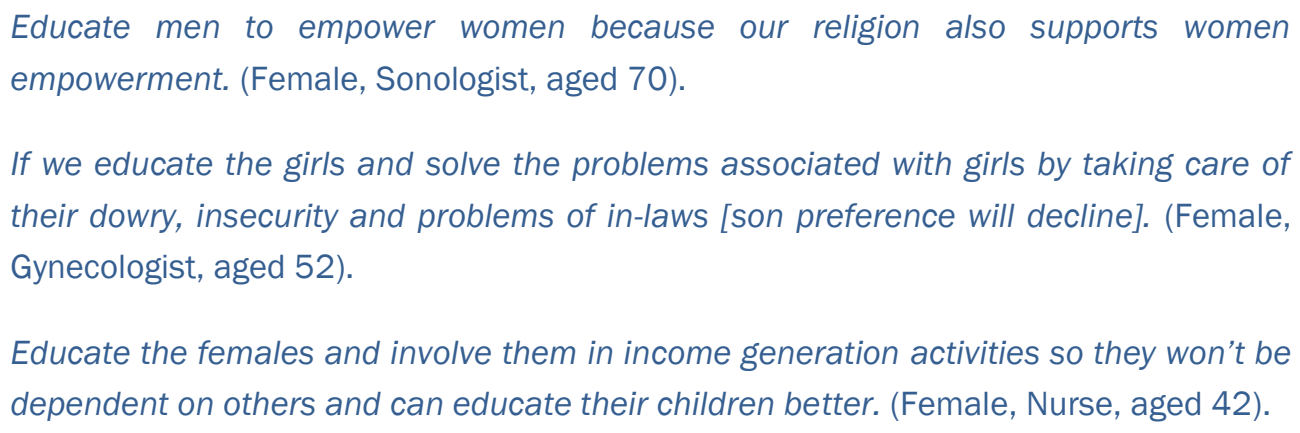

However, the remaining four respondents were of the opinion that son preference cannot be reduced because sons carry forward the family name and are the leading unit of a family. One of them pointed out that changing the mindset of people enough to reduce son preference would be very difficult.

Among community-level interventions to maintain a balanced sex ratio, the majority of providers said it was important to create awareness about the dangers of sex-selective abortion through a range of interventions, such as:

- Media discussions, morning talk shows and advertisements on female empowerment and the danger of sex-selective abortion;

- Talks by religious leaders/scholars on the Islamic view of sex-selective abortion according to the Quran and Sunnah; 
- Training of social workers who can talk to communities about the hazards of sex-selective abortion;

- Counseling programs for men and women by community-level providers regarding the value of girl-children and women, and the danger of sex-selective abortion; and

- Provision of free female education.

Interestingly, one provider (Female, Gynaecologist, aged 46) suggested that public awareness programs should be conducted to convey that husbands are "responsible" for the sex of the baby, and women should not be blamed for it.

\section{Legislation to Restrict Fetal Sex Disclosure}

Respondents were asked how the practice of fetal sex disclosure could be checked, and whether a law should be introduced against it. Ten providers were of the opinion that, if a trend of sex-selective abortion were to develop in Pakistani society, there should be such a law, and it should be vigilantly implemented based on stringent monitoring. Moreover, one provider opined that if any action is taken against some providers, it should be widely publicized for a deterrent effect.

However, one of the respondents was of the view that disclosure of the sex of the fetus was not in itself a negative practice and should not be prohibited in any circumstances.

"I don't think there should be any law. I am not against disclosing the sex-it is the patient's right to know, but it is their [subsequent] behavior that makes us avoid disclosing. Unless and until there are wrong intentions in asking the sex, there is no harm in telling. (Female, Gynaecologist, aged 58).

Another respondent said that the issue should be discussed widely on media talk shows and different forums to spread awareness among the masses.

\section{Sensitization and Training of Providers}

Interviewees were asked what sort of programs they thought needed to be conducted at provider level to ensure that the sex ratio in the district remained or became balanced. Ten respondents said that information and training should be imparted to healthcare providers to improve their own understanding of the value of girls and the dangers of sex-selective abortion. They should be trained how to counsel women asking for sex-selective abortion about the hazards of such abortions and the importance of girls. They should also be provided with correct religious rulings about the value and importance of daughters/girls in Islam.

A respondent suggested that senior providers should train junior colleagues regarding the law of abortion, hazards of sex selection abortions and the value of girls and women. Another provider was of the opinion that, should a trend of sex-selective abortions take root, workshops for healthcare providers should be conducted to discuss the pros and cons of disclosing fetal sex, and it should be discussed at other forums as well. 


\section{Engage influential opinion leaders to address son preference}

Health care providers suggested the involvement of influential opinion leaders in changing attitudes about sons and daughters, in advocating for a balanced sex ratio, and in raising community awareness about the dangers of sex selective abortion. They recommended, for example, that influential individuals appear in media discussions, morning talk shows and that messages relating to female empowerment and the danger of sex selective abortion are widely publicised in the media. They also recommended the engagement of religious leaders/scholars on the Islamic view of sex selective abortion according to the Quran and Sunnah, suggesting that communities were likely to respond to messages from religious leaders about equal treatment of sons and daughters and the dangers of sex selective abortion. Several health care providers also called for the training of social workers and frontline health workers and engaging them in raising community awareness and counselling individual couples about the value of girls and women, and the dangers of sex selective abortion. 


\section{CONCLUSIONS}

The findings of this study indicate that strong son preference persists in Pakistani society. It influences fertility decisions, currently manifesting as higher fertility for the sake of more sons. It also results in significant discrimination by parents against their daughters, leading to nutritional, health and educational neglect and higher mortality among girls, as reflected in the country's skewed child sex ratio.

However, there is very little evidence in literature to suggest that son preference is leading to sex-selective abortions in the country. The exploratory study conducted in Karachi also confirms that sex-selective abortions are not perceived to be a common practice. Fourteen out of the fifteen seasoned healthcare providers interviewed were certain that this practice is not occurring in Karachi. Although they admitted that illegal abortions take place and that some women would abort female fetuses if they could, they were confident that this intent was not widespread and, moreover, could not easily be acted upon because available ultrasound technology cannot detect the sex of the fetus until the second trimester of pregnancy, when abortion becomes much more complicated.

It is important to understand this constraint. Since abortion is illegal in Pakistan, abortion services are largely offered by 'backstreet' providers who are often not sufficiently trained to conduct safe procedures. The difficulty and risk entailed in abortion increases greatly in the second trimester. At this stage, it also becomes religiously impermissible to have an abortion unless the mother's life is threatened; the possible legal consequences of an abortion attain greater proportion as well. For these reasons, the majority of induced abortions in Pakistan are performed in the first trimester of pregnancy, before the sex of the fetus can be determined, and therefore cannot be attributed to sex selection.

This explains why healthcare providers do not view the rising demand for fetal sex disclosure, or its fulfillment, as a worrying phenomenon. The demand for disclosure is attributed to parents' natural curiosity and desire to be prepared, and not to a wish to preempt female births. Likewise, where providers avoid disclosing the sex of the fetus, risk of sex-selective abortions is not mentioned as a reason; such non-disclosure is driven by the religious belief that the sex of a child should not be known before its birth or represents an administrative precaution against disappointment or anger among parents over erroneous ultrasound results. Nevertheless, most of the interviewed healthcare providers held that if a trend of prenatal sex selection were to arise in Pakistan, fetal sex disclosure would need to be strictly regulated.

Given the lack of evidence for significant prevalence of sex selection in Karachi, other explanations should also be explored for the city's skewed sex ratio at birth. At 107.5, Karachi's SRB is not too far beyond the acceptable range of 102 to 107 . In fact, respondents to the qualitative study were quite skeptical that any distortions existed at all. On the other hand, underreporting of female births is a recognized issue that past demographic surveys and censuses have had to contend with. Investigating the sex ratio at birth in the country, Mahmood (2007) found this underreporting to be a significant problem in surveys conducted between 1990 and 2003. On these grounds, the improvements in sex 
ratios implied by the results of the latest PDHS (compared to the last survey in 2006-07) were attributed to better reporting rather than changed demographic realities. It is possible that these reporting difficulties have proved more intractable in Karachi, which has an enormous and heterogeneous population, and where surveyors must navigate extensive ghettoization and socioeconomically diverse microcosms with varying degrees of urbanization.

While the current study indicates that son preference is not distorting sex ratios at birth at present, it also suggests that this situation could change. The desire to abort female fetuses is there in Pakistan, albeit on a limited scale. Fear of ill-treatment for bearing another daughter leads women to abort fetuses before their sex can be determined. Such behavior may not skew sex ratios at birth but represents a clear intent to avoid female-and not male-births. Several remarks of the providers also implied that they at times discern an inclination on the part of their clients to abort female babies. For example, a nurse said she counsels parents against termination of the pregnancy if they intend it, while another provider said she delays sex disclosure until it is "too late" to abort the fetus. One provider was of the view that $10-20 \%$ of illegal abortions occurring in Karachi were sex-selective, while another speculated that abortion service providers can probably tell that the abortion is sex-selective when the husband is very inquisitive about the sex of the fetus.

Collectively, the perceptions reported by healthcare providers indicate that willingness to abort female fetuses exists but not on a significant scale. There is no observable trend of gender-biased sex selection at general health facilities. The fact that available ultrasound technology cannot detect the sex of the fetus in the first trimester, the difficulty of aborting at later stages, and the higher risks of obtaining illegal abortion services from unregulated providers are seen to be important barriers to sex-selective abortions.

In view of the high incidence of abortion in Pakistan and the distortions in the child sex ratio, there is a need to be vigilant. Further decline in fertility-for which there is significant scope-could compel couples to look harder for ways to select the gender of their child, leading to greater demand and supply of more sophisticated fetal sex detection technologies. Likewise, developments that make it easier to conduct abortions in the second trimester could result in increased recourse to sex-selective abortion. Should these possibilities open up, the law and order machinery is unlikely to suffice in controlling the problem: the lack of knowledge expressed by this study's respondents regarding the present abortion law, their view that most health professionals are similarly unaware of the law, and their observation that there is virtually no enforcement of the law suggest that no effective legal barriers exist to check sex-selective abortions if they are, in fact, attempted.

It is therefore very important that healthcare providers be sensitized to the risks and implications of son preference and sex-selective abortions, and encouraged to develop farsighted policies and protocols to minimize the risk of this practice taking root. There is also a need for creative behavior change communication programs that emphasize the moral value and religious endorsement of raising girls well, and highlight the important socioeconomic contributions they can grow up to make when they receive the same care and consideration as boys. Until parents stop discriminating between their sons and daughters, the state and civil society must continue to fill the gap in the care of girls through special programs to support their adequate nutrition, health, education and economic empowerment. 
In summary, provider perspectives suggest that gender biased sex selection and sex selective abortion, while rare, are not entirely absent in Karachi. The pre-conditions for these practices exist: son preference persists, the small family norm is prevalent, and the practice of disclosing the sex of the foetus, while discouraged by some, is widespread.

As a largely illegal activity, abortion is a difficult area to investigate in Pakistan, but efforts must be made to better understand the current motivations of abortion clients and the perceptions of providers. A closer study of the incidence of abortions occurring after the second trimester would furnish a clearer picture of the extent to which son preference is currently affecting demographic outcomes. 


\section{References}

1. Ahmed, A. (1990). Gender differentials in access to health care for Pakistani children, Volume 1, Islamabad, UNICEF

2. Bongaarts, J. (2013). The implementation of preferences for male offspring. Population and Development Review, 39(2), 185-208.

3. Casterline, J. B., Sathar, Z. A., \& Haque, M. (2001). Obstacles to contraceptive use in Pakistan: A study in Punjab. Studies in family planning, 32(2), 95-110.

4. Fatmi, Z., \& Avan, B. I. (2002). Demographic, socio-economic and environmental determinants of utilisation of antenatal care in a rural setting of Sindh, Pakistan. JOURNAL-PAKISTAN MEDICAL ASSOCIATION, 52(4), 138-142.

5. Federal Bureau of Statistics. (2000). Pakistan Integrated Household Survey Round 3: 19981999, Islamabad, Pakistan.

6. Fikree, F. F., \& Pasha, O. (2004). Role of gender in health disparity: the South Asian context. Bmj, 328(7443), 823-826.

7. Gangadharan, L., \& Maitra, P. (2000). Does child mortality reflect gender bias? Evidence from Pakistan. Indian Economic Review, 35(2): 113-131.

8. Gilles, K., \& Feldman-Jacobs, C. (2012). When Technology and Tradition Collide: From Gender Bias to Sex Selection. Population Reference Bureau.

9. Government of Pakistan (2013). Pakistan Labour Force Survey 2012-13: Statistical Division, Pakistan Bureau of Statistics, Islamabad.

10. Guilmoto, C. (2011) Sex imbalances at birth: Trends, consequences and policy implications, Hano - UNFPA revised presentation 2011, (accessed on 04/02/2014)

11. Guilmoto, C. Z. (2009). The sex ratio transition in Asia. Population and Development Review, 35(3), 519-549.

12. Hudson, V. M., \& Den Boer, A. (2005). Missing women and bare branches: gender balance and conflict. Environmental Change and Security Program Report, (11), 20-24.

13. Hunte, P. A., \& Sultana, F. (1992). Health-seeking behavior and the meaning of medications in Balochistan, Pakistan. Social Science \& Medicine, 34(12), 1385-1397.

14. Hussain, R., Fikree, F. F., \& Berendes, H. W. (2000). The role of son preference in reproductive behaviour in Pakistan. Bulletin of the World Health Organization, 78(3), 379-388.

15. Klasen, S., \& Wink, C. (2002). Missing Women: A Review of the Debates and an Analysis of Recent Trends. Available at SSRN 321861.

16. Mahmood, N., \& Ringheim, K. (1996). Factors affecting contraceptive use in Pakistan. Pakistan Development Review 35(1): 1-22. 
17. Muhammad, A. (2009). Does sex of children matter? Implications for Fertility in Pakistan. Journal of biosocial science, 41(01), 39-50.

18. NIPS and ICF International. (2013). Pakistan Demographic and health Survey 2012-13. Islamabad. Islamabad and Calverton, Maryland, USA: National Institute of Population Studies.

19. Nosheen, H., Schellmann, H. (2012). Abandoned, Aborted, or Left for Dead: These Are the Vanishing Girls of Pakistan, The Atlantic, (accessed on 28/3/2014) http://www.theatlantic.com/international/archive/2012/06/abandoned-aborted-or-left-for-deadthese-are-the-vanishing-girls-of-pakistan/258648/

20. Pakistan Bureau of Statistics. (2013). Pakistan Social and Living Standards Measurement (PSLM) Survey 2012-13. Government of Pakistan, Islamabad.

21. Qadir, F., Khan, M. M., Medhin, G., \& Prince, M. (2011). Male gender preference, female gender disadvantage as risk factors for psychological morbidity in Pakistani women of childbearing age-a life course perspective. BMC public health, 11(1), 745.

22. Royan, R., Zaidi, B. (2011). Trends in sex selection in Pakistan, UNFPA: Report of the International Workshop Skewed Sex on Ratios at Birth: Addressing the Issue and the Way Forward, Ha Noi, Vietnam.

23. Sathar, Z. A. (2007). Stagnation in Fertility Levels in Pakistan. Asia-Pacific Population Journal, 22(2), 113-131.

24. Sathar, Z.A., Singh, S., Shah, Z.H., Rashida, G., Kamran, I. and Eshai, K. (2013). Post-Abortion Care in Pakistan: A National Study. Islamabad: Population Council.

25. Sayah, R. (2011). Killing of infants on the rise in Pakistan, CNN News, (accessed on 28/3/14) http://edition.cnn.com/2011/WORLD/asiapcf/07/20/pakistan.infanticide/

26. Sen, A. (1990). More than 100 million women are missing. The New York Review of Books 37(20), 61-66.

27. UNFPA, 2012, Sex Imbalances at Birth: Current trends, consequences and policy implications

28. Zaidi, B. (2013). In The Pursuit Of Sons: Sex-Selective Abortion And Differential Stopping In Pakistan. Department of Sociology in the College of Arts and Sciences. University of North Carolina at Chapel Hill. https://cdr.lib.unc.edu/indexablecontent/uuid:11f30683-826d-4fe48dc0-be3f2e285b6e.

29. Zubair, F., Dahl, E., Shah, S. S., Ahmed, M., \& Brosig, B. (2007). Gender preferences and demand for preconception sex selection: a survey among pregnant women in Pakistan. Human Reproduction, 22(2), 605-609. 